contact with European economy. Systems characteristic of the following periods are not, to the same extent, original or distinctive in relation to their time. Hence the importance of studying the elementary systems on which the successive ones have been built. As a first approximation, five economic systems of the first period will be the subject-matter of separate studies: substantive, predatory, trade, slave, and royal monopolies. Some of these systems, which ate themselves the result of contacts, will be studied, from the simplest to the most complex, without assuming that all the systems are evolving along a continuous line of development. The comparative method does not allow for restriction to a delimited area. Some systems located in outlying areas, in relation to the geographical axes of the research, may offer cases of more advanced development, therefore clearer than those observed in our given area. The intention is therefore to study the various systems met in Western Africa and to deepen our knowledge and understanding of these through comparison with similar systems existing in other areas. By so doing we hope to satisfy the dual theoretical requirement of a comparative study and of an inter-relational study with an historical content.

This particular study will not be 'inter-disciplinary' although we intend to use specialists as consultants for the research. Inter-disciplinary studies do not lead usually to a synthesis and do not provide the training of students capable of such syntheses. We believe it is more appropriate, given the subject-matter, for each student engaged in this research to specialize in a particular problem, i.e. one economic system to each student, who will have to direct himself among the related disciplines and to assimilate the workings of a system to the point of 'predicting' its transformations under the impact of other systems or under the effect of given events. The value of some of these 'predictions', when it is possible to test them against actual historical events, will indicate the validity of the constructed models which will be extended to other societies of the same type.

(Abridged from a fuller statement available from Dr. C. Meillassoux, 2 rue de Mirbel, Paris Ve)

\title{
Field Research in Zambia
}

Fr. B. Strfaniszyn, of Duquesne University, Pittsburgh, author of The Social and Ritual Life of the Ambo of Northern Rhodesia, has been awarded a Fulbright-Hays Fellowship for three months' field research in Zambia (July-September r966), among the Ambo, Tonga, Soli, and Chikunda. He is investigating primitive medicine, communal drinking, and folklore for a sociological analysis and a comparative study based on this new material and his earlier data on these peoples.

\section{The Hadza: An Ethnographic Film about an East African Hunting and Gathering Tribe}

Thrs film, a co-operative venture between a film director and an anthropologist, is an attempt to produce a detailed and systematic description of the way in which an isolated East African tribe obtain their food by hunting game animals and by collecting wild fruits, roots, and the honey of wild bees. The Eastern Hadza, shown in this film, number some 400 people and, until a settlement scheme was initiated in 1964 , they moved in small nomadic groups over an area of about a thousand square miles to the east of Lake Eyasi, just south of the equator in East Africa. The film was made during a four-month visit after the completion of more than two years' continuous anthropological research among them. Copies (I6 mm., black and white, 40 minutes running time) are available from Sean Hudson, 